\title{
Forecast of the position of promising sand reservoirs in the cross-section of the carboniferous gas-bearing stratum
}

\author{
Viacheslav Lukinov ${ }^{1, *}$, and Mykola Zhykaliak $^{2}$ \\ ${ }^{1}$ Institute of Geotechnical Mechanics named by N. Poljakov of National Academy of Sciences of \\ Ukraine, 49005, Dnipro, Simferopolska Str., 2a, Ukraine \\ ${ }^{2}$ State Regional Geological Enterprise «Donetskgeologiya» of the State Service of Geology and \\ Mineral Resources of Ukraine, 84511, Bahmut, O. Sybirtseva, 17, Ukraine
}

\begin{abstract}
The results of the study of the influence of overburden stress in a solid mass undisturbed by mine workings on the compaction of sandstones within mine fields, exploration areas of Donbas coal deposits and some gas condensate and oil and gas condensate deposits of the Dnipro-Donets Depression (DDD) are presented. Regularities of changes in gas-bearing properties of porous reservoirs with the increase of overburden stress in an undisturbed solid mass, or its decrease in mine conditions are considered. The possibilities of rapid assessment of the forecast position of prospective sand reservoirs in the cross-section of the gas-bearing stratum are shown. Methods are proposed for calculating the position of sandstones of gas-bearing stratum, in which it is advisable to search for gas accumulations and its extraction in the coal and gas, oil and gas condensate and gas condensate fields of Donbas and DDD.
\end{abstract}

\section{Introduction}

The growth of the country's economy is impossible without providing it with the necessary resource base, in which the fuel and energy component plays an important role, orienting itself, in many respects, to the traditional hydrocarbon energy raw materials - coal, oil, and gas. The article discusses current issues currently facing the geology of hydrocarbon gases, aimed at involving additional volumes of energy carriers in the country's fuel and energy balance and affecting the problem of finding gas promising sand collectors. First of all, these questions concern traditional and unconventional energy carriers, among which, undoubtedly, methane of coal mines (CMM - coal mine methane) and methane of closed mines (CAM - coal abandoned methane) occupies an important place. The relevance of these issues is confirmed by the fact that the extraction and use of methane from coal mines is not only possible, but also implemented on an industrial scale in many countries, including Ukraine. Another group of questions is related to the problem of the formation of traditional and unconventional hydrocarbon traps, with a detailed study of the migration routes of hydrocarbon gases, the conditions of their accumulation and preservation, which,

\footnotetext{
*Corresponding author: lukinovv@i.ua
} 
in turn, requires a detailed study of the processes and factors of the formation of hydrocarbon deposits and accumulations. The substantiated scientifically and practically confirmed answers to the above questions will help develop some promising directions for searching for hydrocarbon accumulations, choosing criteria for assessing the gas content of sand reservoirs and calculating the location parameters of the most promising gas-saturated zones in the cross-section of coal and gas, gas and gas condensate fields, which will allow to organize more reasonably and develop their effective development.

The objective of the work is to study the effect of overburden stress in the undisturbed (intact) solid mass on the compaction of sandstones as potential reservoirs in the exploration areas of Donbas coal deposits and some hydrocarbon gas deposits in the Dnipro-Donets Depression (DDD); in the establishment of regularities of change in gasbearing properties of porous reservoirs with an increase in the current depth cover of rocks; in the development of methods for the calculation and rapid assessment of the forecasted position in the cross-section of gas-bearing stratum of sand reservoirs, promising for exploration and development of hydrocarbon gas deposits within the existing coal-gas, oil and gas condensate and gas-condensate fields.

\section{Methodology}

The methodological basis of the research was the systematization, analysis and synthesis of geological data characterizing the reservoir properties of sandstones, the calculation of the depths of the maximum potential gas saturation of sandstones in gas condensate and oil and gas condensate deposits of DDD and their comparison with similar deposits in Donbas. When processing the geological and calculated data, methods of mathematical statistics were used, on the basis of which the corresponding graphs were built, regularities were studied, and conclusions were drawn.

Earlier studies [1,2] allowed to establish the regularities of changes with depth of reservoir properties and potential gas saturation of sandstones in some geological and industrial areas of Donbas, which served as the basis for calculating the predicted values of depths in the cross-section of coal-bearing stratum, favorable for the accumulation of significant amounts of methane in sand reservoirs.

With the increase in the current depth of coal-bearing sediments, overburden stress increases, due to the weight of overlying rocks, which leads to their compaction, deterioration of gas saturated properties, decrease in open porosity of sand reservoirs, increase in their bulk density. Within the same geological area and one depth interval, which reflects the same degree of catagenetic changes in rocks, the differences in the values of their reservoir properties mainly characterize the differences in the formation conditions expressed in sandstone belonging to one or another genetic type. The effect of tectonics can manifest itself in individual layers of sandstones, for example, in the arches of anticlinal structures, when the fracture hollowness that occurs during the deformation process of the layers increases the overall hollowness (porosity) and causes the formation of a fracture and porous type [3]. Using the example of analyzing exploration data on Gorlovskyi Deep Site (Donbas), it can be seen that, despite the fluctuations, the open porosity values of sandstones decrease with depth (Fig. 1).

Within one mine field, a site of exploration or a gas field, the depth of occurrence reflects modern lithostatic pressure, and also carries information about paleogravitational and paleotectonic pressure, which changed the reservoir properties of rocks. For the conditions of Donbas, the open porosity of sandstones, on average, decreases by $3 \%$ for every $1000 \mathrm{~m}$ of increase in modern depth [2]. 


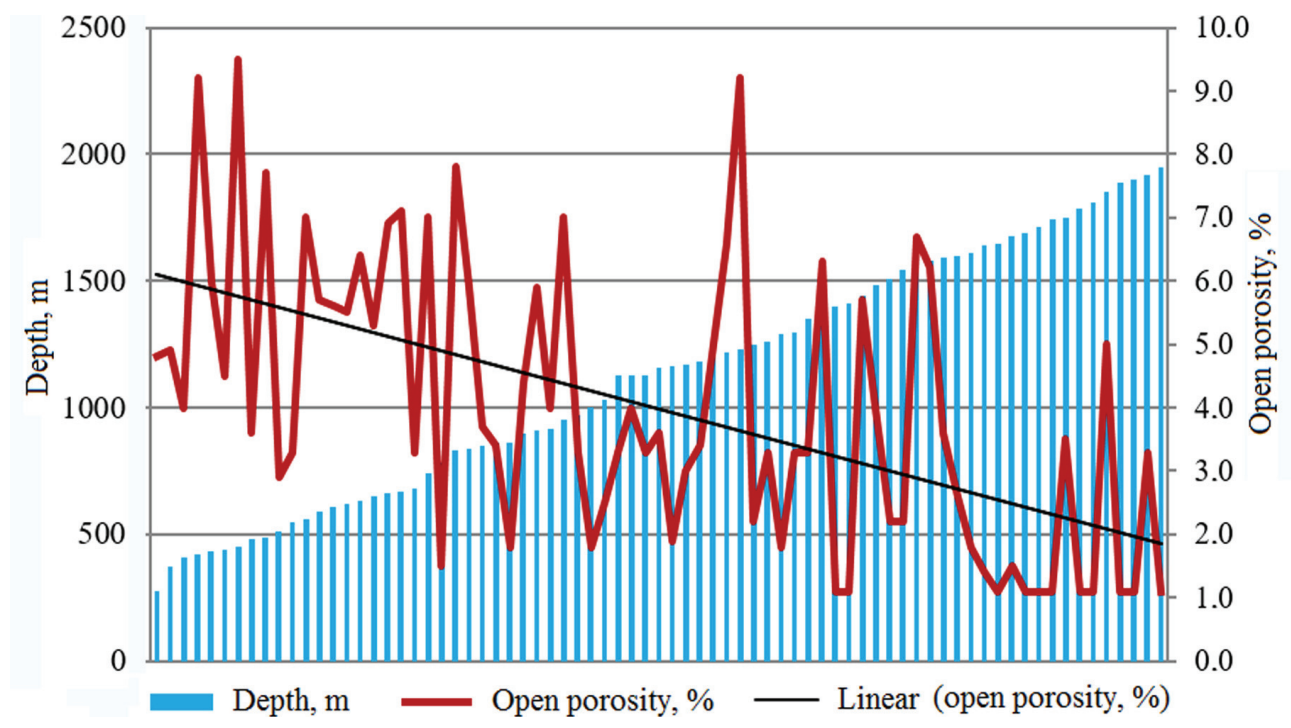

Fig. 1. The graph of changes of open porosity of sandstones with the depth of their occurrence in Gorlivskyi Deep Site (Donbas).

The sand saturation of the sandstones depends on two main factors - gas pressure and gas capacity of the reservoir, which is controlled by the effective porosity, which is the part of open porosity that is not filled with moisture. However, reliable determination of the effective porosity of sandstones from cores of exploration wells is difficult due to penetration of drilling mud filtrate into the core, therefore, the values of open porosity are used as an indicator of reservoir properties, including the calculation of the maximum potential gas saturation. Taking into account the fact that the absolute (weight) moisture of rocks decreases with depth, this approach can be used both for generalized assessments of the maximum potential gas saturation of Donbas sandstones, which have low porosity and low permeability, and for predicted assessments for oil and gas condensate fields of DDD.

In DDD hydrocarbons during migration filled the most favorable to accumulation highly porous sandstones; therefore, within one deposit, reservoirs of productive horizons are characterized by elevated open porosity values. This causes a smaller variation in the depths of occurrence of the open porosity values of the sandstones of productive horizons within one deposit, or a group of deposits located in the same geological conditions. The contraction of highly porous sandstones at the depth which is expressed in the reduction of open porosity values observed here [4], which is clearly apparent in the example of sand reservoirs of Novoselivskyi and Proletarskyi condensate deposits and Kremenivskyi and Eastern-Novoselivskyi oil and gas condensate deposits timed in geological relation to Zachepilivsko-Leventsovskyi structural swell within Rudenkivsko-Proletarskyi oil and gas region (Fig. 2).

The change in the coefficient of open porosity of sandstones $K_{p}$ with increasing depth of sandstones $H$, is described by the equation of general form:

$$
K_{p}=a-b H
$$

where $a$ and $b$ - equation coefficients.

For the conditions of Novoselivskyi, Estern-Novoselivskyi, Proletarskyi and Kremenivskyi deposits, this equation has the form: 


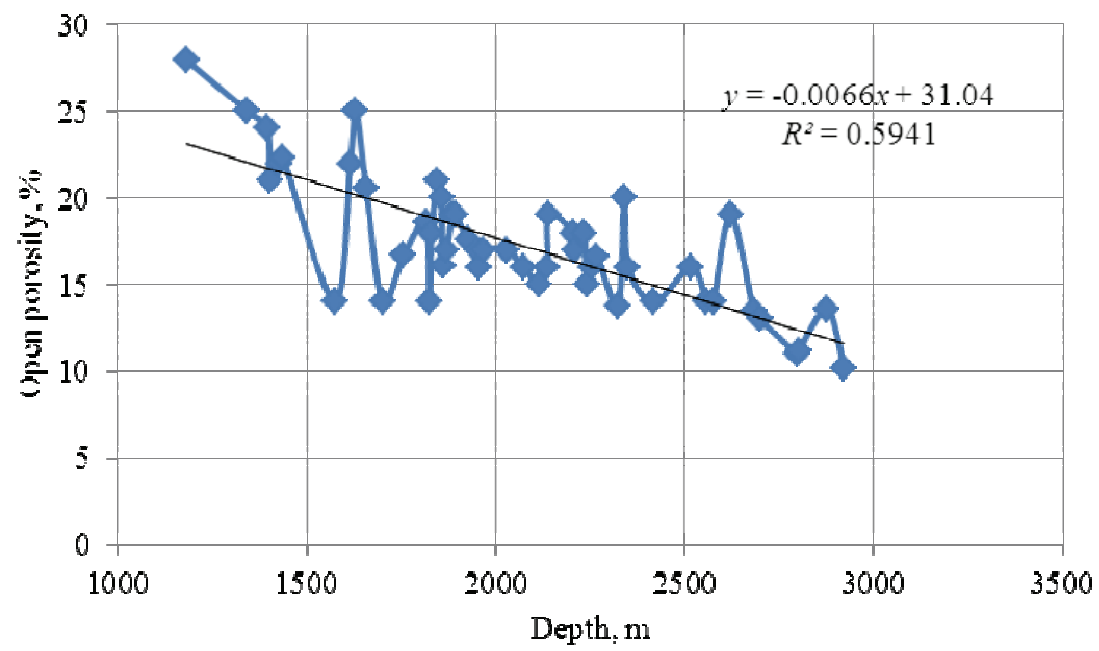

Fig. 2. The graph of changes of the open porosity of sandstones with the depth of their occurrence in Novoselivskyi, Eastern-Novoselivskyi, Proletarskyi and Kremenivskyi deposits.

$$
K_{p}=-0.0066 H+31.04 \text {. }
$$

The vast majority of hydrocarbon deposits of DDD, with the exception of individual fields with abnormally high gas pressures, such as Machukhskoe, are characterized by gas pressure equal to or approximately equal to hydrostatic. Thus, as the studies have shown, two parameters that determine the gas-bearing capacity of sandstones, with increasing depth, change in opposite directions. The open porosity of sandstones with increasing stratification depth, which reflects the action of both modern and paleogravitational pressure - decreases, and the gas pressure in the pores, as a result of the fact that fluid filtration processes and gas diffusion in the solid mass proceed for a long time increases.

Gas does not occupy the entire volume of open pores. The part of this volume is filled with liquid fluid, (mostly by water, but sometimes, especially at gas condensate and oil and gas condensate fields by liquid hydrocarbons, therefore, the open porosity of sandstones characterizes their maximum possible hydrocarbon capacity, and taking into account gas pressure, maximum possible, or potential gas saturation. Fluid pressure, in particular gas, in sandstones with depth increases at straight-line correlation. In sand reservoirs of productive horizons of the above-mentioned fields of DDD gas pressure is hydrostatic and increases in direct proportion to the increase in the depth of their occurrence (Fig. 3).

The change of gas pressure $(P)$ with stratification depth, in general terms, is expressed as:

$$
P=c H
$$

where $c$ - equation coefficient.

The maximum potential gas saturation of sandstones $G_{s}$ can be represented as a function $f$ of the product of the open porosity coefficient $K_{p}$ and gas pressure $P$ :

$$
G_{s}=f\left(P \cdot K_{p}\right) \text {. }
$$

The maximum potential gas saturation of sandstones in the cross-section of the gasbearing strata in the coal deposits of Donbas varies with the depth in a parabolic law: it increases in the upper horizons to a maximum, and then decreases with the depth to the complete absence of gas. In [1], an equation of general form is given: 


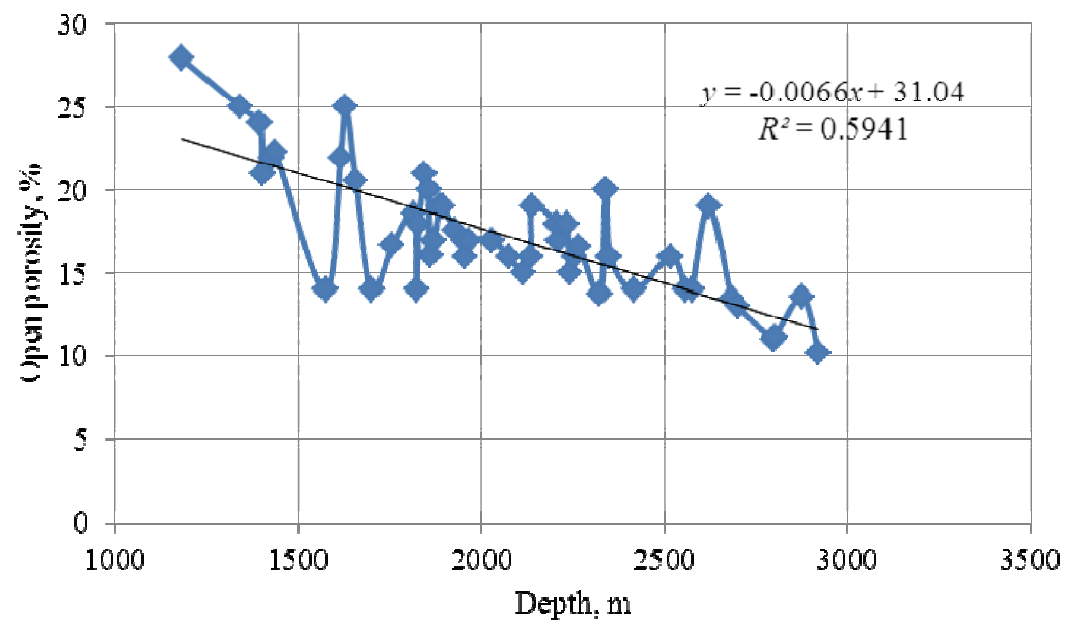

Fig. 3. The graph of changes of gas pressure with the depth of productive sand horizons at Novoselivskyi, Eastern-Novoselivskyi, Proletarskyi and Kremenivskyi deposits.

$$
H_{\text {g.max }}=a /(2 b),
$$

the solution of which allows to determine the position of the depth $H_{g . \max }$ of the maximum potential gas saturation $G_{\text {s.max }}$ in the cross-section of the gas-saturated stratum.

\section{Discussion of the outcomes}

Formula (5) was proposed for coal deposits of Donbas, provided that the absence of gas content corresponds to zero open porosity, and in the deposits under study of DDD the minimum open porosity of productive reservoirs is $8-10 \%$. In gas and gas condensate fields, the potential gas saturation of reservoirs is realized and manifested in the values of the maximum concentration of gas reserves at certain depths. A generalized analysis of changes in the gas saturation of the cross-section of gas-bearing strata using the example of sand collectors of the above gas condensate and oil-gas condensate fields of DDD [4] showed that the specific gas saturation of two hundred meter intervals of the cross-section also varies according to a parabolic law (Fig. 4). The actual depth of the upper boundary of the gas-bearing stratum of the group of fields under consideration is $1,181 \mathrm{~m}$, and the lower limit of the gas-bearing stratum is $2,922 \mathrm{~m}$. The thickness of the gas-bearing stratum is $1,740 \mathrm{~m}$, and its middle part is confined to the depth of $2,050 \mathrm{~m}$. The thickness of the maximum gas saturation of sandstones is $600 \mathrm{~m}$, or $34 \%$ of the thickness of the gas-bearing stratum, and its middle is located at a depth of approximately $2,100 \mathrm{~m}$. The depth of the middle part of the interval is maximum gas-saturated sandstones and the middle part of the gas-bearing stratum practically coincide $-2,100$ and 2,050 $\mathrm{m}$, and the estimated depth of the maximum potential gas saturation of sandstones, determined by formula (5) using the equation coefficients (1) is $2,350 \mathrm{~m}$. In works [1, 2], the mechanism verification of forming changes in the maximum potential gas saturation of sandstones of a parabolic type, however, there is no analysis of the relationship between the position of the most saturated part of the section and the total thickness of the gas-bearing stratum. The graph (Fig. 4) shows that the actual amount of gas contained in $1 \mathrm{~m}^{3}$ of the gas-bearing thickness, at intervals of 200 meters, increases to the middle part of the section, with some displacement towards the overlying horizons. In this case, the gas-bearing stratum is conditionally 
considered as a set of imaginary reservoirs with a productive collector with a capacity of two hundred meters.

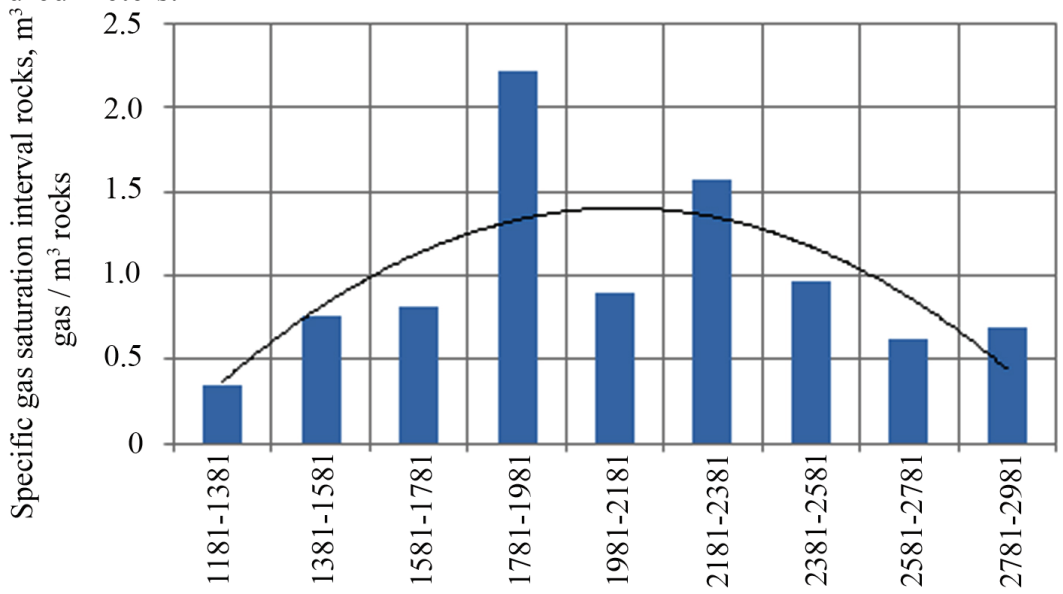

Depth interval, $m$

Fig. 4. The graph of changes in the actual specific gas saturation of the cross-section of gas-bearing stratum within the 200-meter intervals at Novoselivskyi, Eastern-Novoselivskyi, Proletarskyi and Kremenivskyi deposits.

In the case of the deposits under consideration of DDD, related to the geological structure of the same order within the same oil and gas-bearing region, there is a regular increase in the number of productive horizons, which is also parabolic in nature (Fig. 5).

The depths at which the number of productive horizons increases in the cross-section coincide with the depths, $1,800-2,400 \mathrm{~m}$, at which the increased values of specific gas saturation stratum are noted.

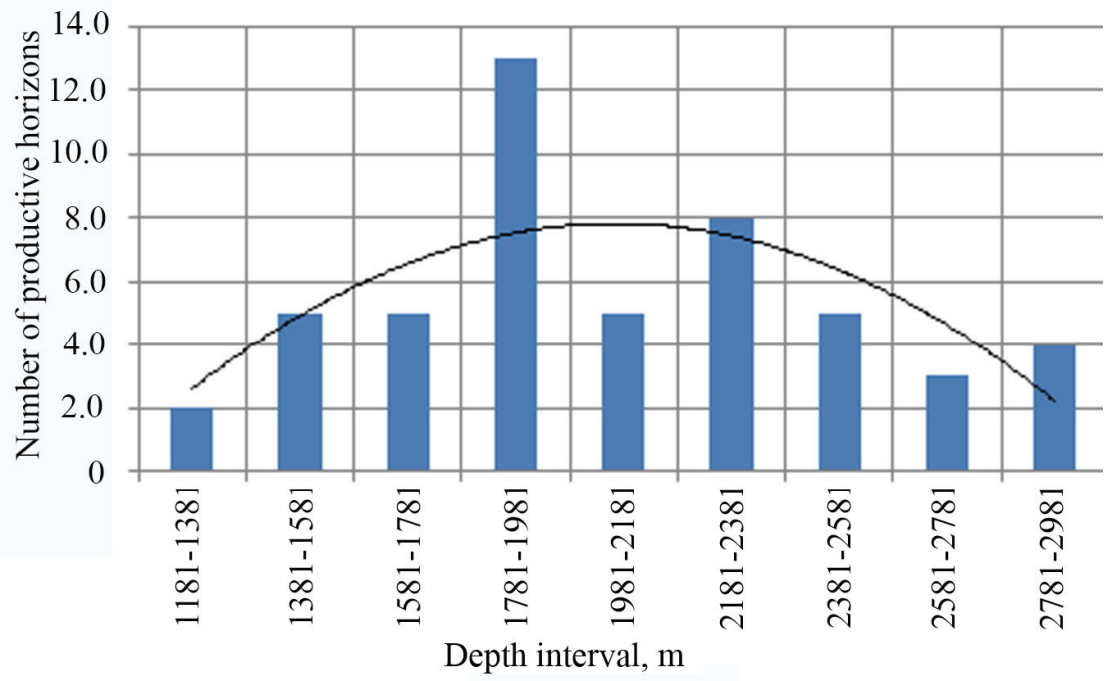

Fig. 5. The graph of changes in the number of productive sand horizons at the intervals of depths at Novoselivskyi, Eastern-Novoselivskyi, Proletarskyi and Kremenivskyi deposits.

The obtained results allow us to consider the values of the thickness of the gas-bearing stratum and the depths of its upper and lower limits as predicted for establishing the position of the most gas-saturated sandstones in the cross-section, but it is necessary to take 
into account that, depending on the geological conditions of accumulation and preservation of deposits, the actual position of the maximum gas saturation of productive reservoirs may vary. Thus, gas condensate and oil and gas condensate deposits of DDD, as well as coal deposits, including mine conditions, when the change in gas intensity of the reservoir and the pressure of gas contained in it occur in diametrically opposite directions, the formation of a larger number of productive sand collectors occurs in the middle part of the crosssection of gas-bearing stratum.

By a similar mechanism, processes occur in the rocks of coal-bearing stratum when it is underworked by the face, when the mountain solid mass, due to unloading from the overlying rocks, decompresses, and in the direction from the cavity that occurs after the coal seam is excavated, decompression damps, gas pressure in the rocks increases [5]. Most contrasting, due to the addition of the gravitational component, gas-dynamic characteristics of the solid mass change in the vertical direction, upwards from the declining layer.

The rocks of the undermined stratum are partially unloaded from the rock pressure, experiencing tensile deformations, pore channels open up, increasing the permeability of the solid mass, which is enhanced by cracks. At the same time, methane acquires mobility and migrates from a region with a higher gas pressure, but less permeable rocks, to a region with low gas pressure, but with more permeable rocks and more favorable conditions for the formation of gas accumulations. As a rule, such accumulations are formed in zones capable of holding gas, characterized by signs of gas traps and meeting the requirements of a reservoir in which the reservoir is, as a rule, decompressed sandstone. The effect of filling the decompressed underworked sandstones with methane is most common in mines extracting coal grades $G, Z h, K$, where the rocks belong to the mesocatagenesis stage $\left(M C_{2}\right.$, $M C_{3}, M C_{4}$ ), and tensile deformations increase the existing small natural porous component of the gas capacity of sandstones. Due to the fact that the process of deformation of the roof rocks of the declining coal seam lasts a certain time, the position of the reservoir and screening rocks in space is not constant, depends on the combination of the physical properties of the rocks and their stressed-deformed state, which allows to consider the formation of methane accumulations (CMM and CAM) in the undermined solid mass as a permanent process, and the position of methane release sources, reservoirs, screens and traps - migrating. Roof rocks of the working seam are the main object of the underground current degassing, which is implemented by wells drilled from the mine workings. Coal seams, including satellites, sandstones, siltstones and mudstones, are considered as the objects of methane release. Coal seams and inter-layers (satellites) are powerful natural accumulators of sorbed methane, which are capable of giving it away for a long time and at great distances from the declining layer, but slowly. Argillites, as well as coal seams, contain sorbed methane, but in a smaller amount, are able to release it only in the zones that are intensely disturbed by cracks, in the immediate vicinity over the declining coal seam are not suitable for gas accumulation. Sandstones and siltstones contain mostly free methane, which is able to accumulate in significant volumes in the areas of decompression, when the gas becomes mobile due to the unloading of the solid mass from the rock pressure. The above-described mechanism of methane movement in the underworked solid mass is taken into account when work is organized on the current degassing during the period of face mining. To determine the drilling parameters of degassing wells, it is necessary to know the thickness of the rocks subjected to decompression due to underworking and the distance to the intended reservoirs, from which it is advisable to pump out gas. In the work [6], formulas are given for calculating unloading intervals for the underworked rocks of the coal-bearing stratum, from which gas can be released, accumulating in favorable places, or falling into a degassing well, if it stripped this rock. In particular, for sandstones and siltstones, this interval is calculated by formula:

$$
h_{s}=70 m_{r} \cdot k_{l}
$$


where $h_{s}$ - unloading interval of underworked sandstones and siltstones; $m_{r}-$ mining height of the working coal seam; $k_{l}$ - this coefficient taking into account the effect of the degree of metamorphism on the value of the unloading swell, dimensionless, is selected according to the «Guide ...» [7].

The unloading interval of underworked sandstones is the thickness of the rocks lying above the roof of the mining coal seam, within which all sandstones are decompressed and able to release gas. In the unloading zone, upward from the roof of the declining seam, the reservoir properties of individual layers of sandstones, such as open porosity and permeability, deteriorate and the gas pressure rises [5]. The thickness of the rocks in the unloading sandstone zone is the thickness of the gas-bearing layer, which is produced by the face and is the main source of CMM, or «fast methane», that is, methane entering the mine workings and the worked-out area of the face during coal mining, and as it was shown above, the most favorable position of the reservoir for the formation of methane accumulations, the CMM source in the gas-bearing strata, is its middle part. The middle of the undermined gas-bearing stratum will be located at a distance $h$, which corresponds to:

$$
h=0.5 h_{s}=35 m_{r} \cdot k_{l} \text {. }
$$

For example, for the conditions of mining of coal seam $\mathrm{m}_{3}$ of O.F. Zasyadko Western Face 16 , the calculated capacity of the undermined gas-bearing stratum $h_{s}$ is $126 \mathrm{~m}$, and its middle is located at the distance $h$ of $63 \mathrm{~m}$ from the seam roof $m_{3}$ (Fig. 6).

Drilling of underground wells with a length of $126 \mathrm{~m}$ is a laborious, cost-based and technically challenging task, since it requires, firstly, a considerable amount of working time for drilling, secondly, a special rock-cutting tool (a bore bit) of improved quality, thirdly, to protect the wellbore from his collapse under the action of forces of rock pressure and keeping it in working condition along the entire length. Under the conditions of mining of coal seam $m_{3}$ of O.F. Zasyadko Western Longwall 16, the extraction of methane showed their high efficiency for the wells drilled in the middle part of the gas-bearing stratum, which is located at a distance of about $63 \mathrm{~m}$ from the seam $m_{3}$ in the sandstone roof of $m_{4}{ }^{0} \mathrm{Sm}_{4}{ }^{1}$, showed their effectiveness (Fig.7).

Considering that the thickness $I h$ of the zone of maximum gas saturation of undermined sandstones, or the zone of the CMM accumulation is $34 \%$ of the thickness of the gasbearing stratum, and the depths of their central parts coincide, it is proposed to use the following equation to determine the position $I h$ :

$$
I h=H_{c}-\left(35 m_{r} \cdot k_{l} \pm 0.17 h_{s}\right),
$$

where $H_{c}$ - depth of cover of the declining coal seam.

The position of the zone of maximum gas saturation of subsided sandstones is fixed by the depths of its upper $I h_{u}$ and lower $I h_{l}$ boundaries, which are calculated using the equations obtained after transforming formula (8):

$$
\begin{gathered}
I h_{u}=H_{c}-46.9 m_{r} \cdot k_{l}, \\
I h_{l}=H_{c}-23.1 \cdot m_{r} \cdot k_{l} .
\end{gathered}
$$

For the conditions of extraction of the coal seam $\mathrm{m}_{3}$ of O.F. Zasyadko Mine shown in Figure 6 (depth $1,306 \mathrm{~m}$, bed thickness $1.8 \mathrm{~m}, k_{l}=1$ ), the boundaries of the zone of maximum gas saturation of subsided sandstones, calculated by equations (9) and (10), are located at depths of 1,219 $\mathrm{m}$ and 1,264 m. Within these depths lies either almost all of the sandstone $m_{4}{ }^{0} \mathrm{Sm}_{4}{ }^{1}$, or, in places where there is no coal seam $m_{4}{ }^{1}$, the lower and middle parts of the sandstone $m_{4}{ }^{0} \mathrm{Sm}_{4}{ }^{3}$. 


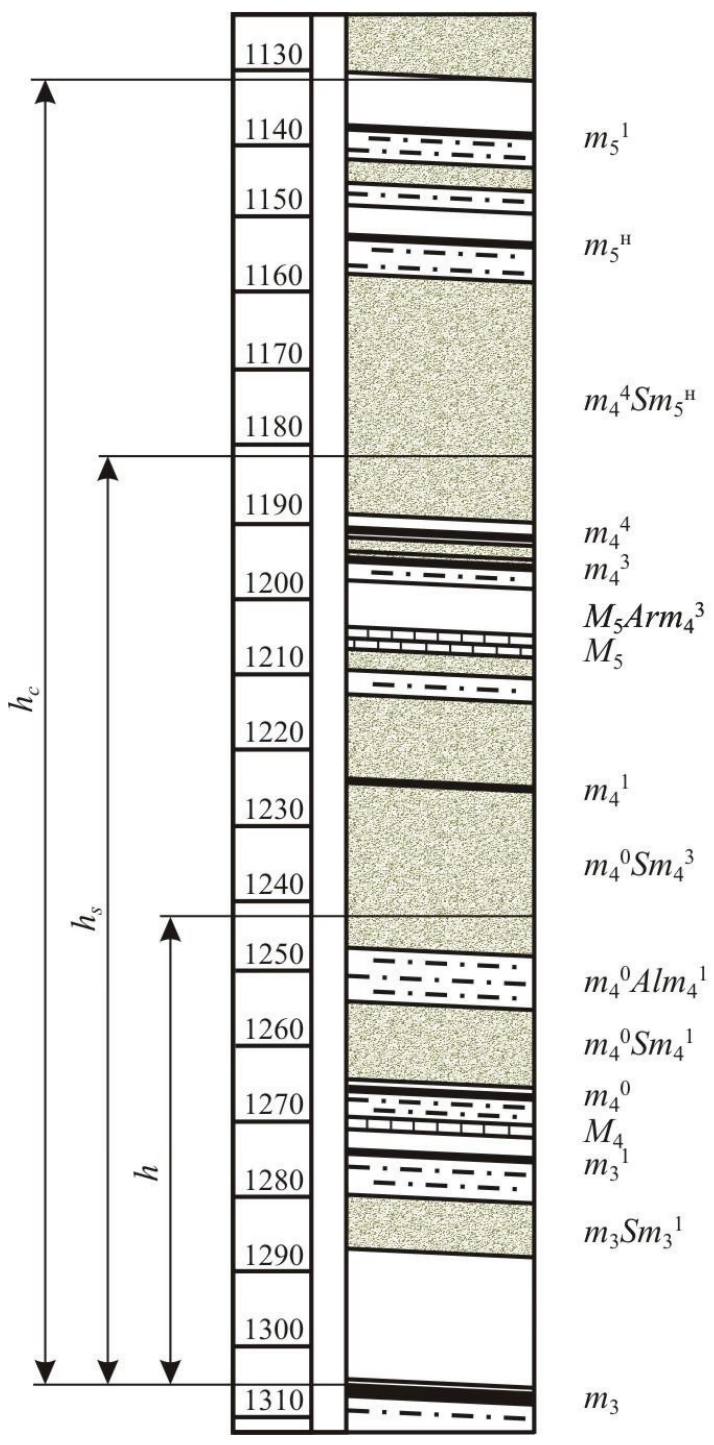

Fig. 6. A cross-section of the coal-bearing stratum, undermined during extraction of seam $m_{3}$ at O.F. Zasyadko Mine.

\section{Conclusions}

It has been established that oil and gas and gas condensate deposits of DDD and coal deposits of Donbas, with increasing depth of cover the change of reservoir gas capacity and pressure contained therein gas occur in diametrically opposite directions, which causes the change of the specific gas saturation of sandstone reservoirs in vertical cross-section of gasbearing stratum under parabolic law. In the fields of DDD, the depth interval in which increased values of specific gas saturation in the cross-section coincide with the interval in which the number of productive horizons increases, and the thickness of the maximum gas saturation interval in sandstones is $34 \%$ of the thickness of the gas-bearing stratum. In the 
rocks of Donbas coal-bearing stratum, when they are underworked by the face, as the reservoir with offset distance from the roof of a declining stratum, the gas intensity and gas permeability of the reservoirs decrease, and the gas pressure increases, which forms a parabolic character of change in the gas saturation of the sandstones subsided by mining works. A new method is proposed for calculating the position of the upper and lower boundaries of the zone of maximum gas saturation of subsided sandstones, which is one of the main accumulation sites and sources of methane input into the mine workings of the CMM source.

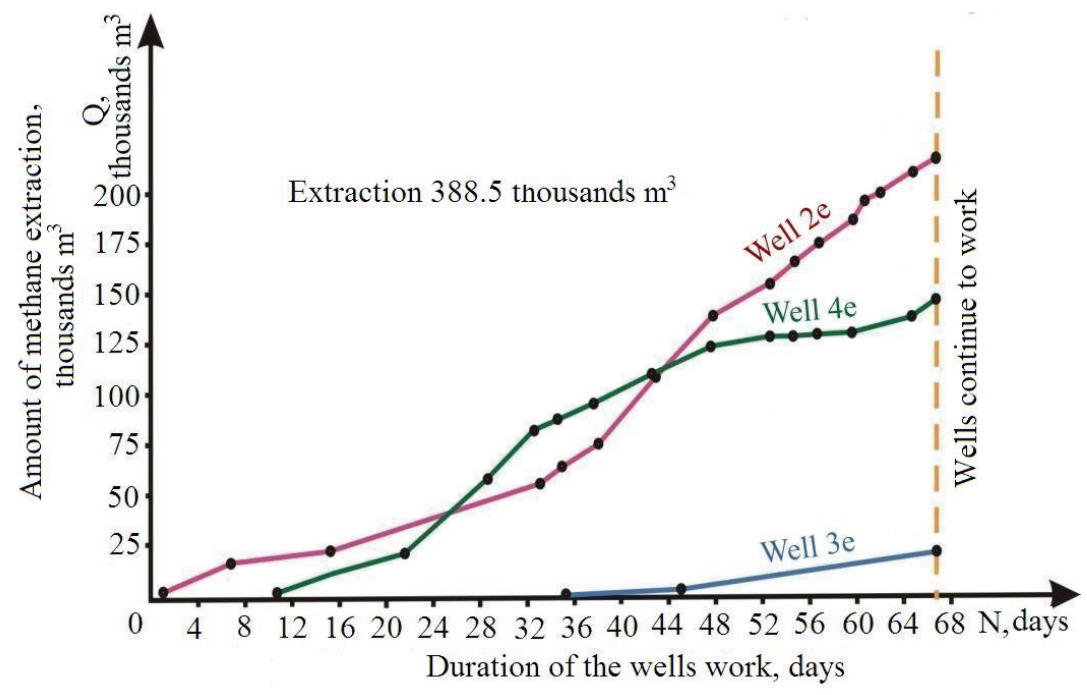

Fig. 7. Some results of the operation of underground degassing wells of the seam at O.F. Zasyadko Western Longwall 16.

\section{References}

1. Lukinov V.V., Zhykalyak N.V. (2005). Prognoznaya otsenka glubin maximalnoy gazonosnosty peschanikov, Geotekhnicheskaya mekhanika (53), 13-20

2. Bulat, A.F., Zvyagilskiy, E.L., Lukinov, V.V., Perepelitsa, V.G., Pymonenko, L.I., Shevelev, G.A. (2008). Ugleporodnyy massiv Donbasa kak geterogennaya sreda, Kiev, Naukova dumka

3. Orlov, A.A, Fedorishin, D.D, Lizun, S.A. (2008). Zakonomernost geneticheskoy svyazi anomalnykh plastovykh davleniy so skladkoobrazovatelnymi tektonicheskimi protsessami v osadochnom chekhle zemnoy kory. Ivano-Frankivsk: "Fakel"

4. Atlas rodovyshch nafty I gazu Ukrayiny v 6 t (1999). Ukrayinska naftogazova akademiya, Lviv (3)

5. Lukinov, V.V. (2006). Metan zakrytykh shakht - problemy I resheniya. Geotekhnicheskaya mekhanika (67), 55-67

6. Lukinov, V.V., Klets, A.P., Bokiy, B.V., Yefremov, I.A. (2010). Prognoz metanovydeleniya iz podrabotannogo ugleporodnogo massivakrovli v vyrabotky vyemochnogo uchastka. Ugol Ukrainy (6), 39-42

7. Rukovodstvo po proektirovaniyu ventilyatsii ugolnykh shakht (1994). Kiev, Osnova 